\title{
Genetic variants conferring susceptibility to Alzheimer's disease in the general population; do they also predispose to dementia in Down's syndrome
}

Ashok Patel ${ }^{1 *}$, Simon D Rees ${ }^{2}$, M Ann Kelly ${ }^{2}$, Stephen C Bain ${ }^{3}$, Anthony H Barnett ${ }^{2,4}$, Anisha Prasher ${ }^{5}$, Humaria Arshad ${ }^{6}$ and Vee P Prasher ${ }^{6,7}$

\begin{abstract}
Background: Down's syndrome (DS) is caused by either complete or partial triplication of chromosome 21, affecting approximately $1 / 1000$ live births, and it is widely accepted that individuals with DS are more likely to develop dementia of Alzheimer's disease (DAD) compared with the general population. Recent collaborative genome-wide association studies of large case control data sets of individuals with and without Alzhemier's disease (AD) have revealed new risk variants for dementia, as well as confirming previously identified risk variants. In this study, nine AD-derived SNPs, near or within the CR1 (rs3818361), BIN1 (rs744373), CD2AP (rs9349407), EPHA1 (rs11767557), CLU (rs1532278), MS4A6A/4A (rs610932), PICALM (rs561655), ABCA7 (rs3764650) and CD33 (rs3865444) genes were genotyped in 295 individuals with DS.

Results: There were no significant associations between these nine GWAS-derived SNPs and DAD in British Caucasian individuals with DS. Interestingly the CR1 rs3818361 variant appeared to be associated with mortality in our cohort, particularly in the subjects without dementia. To our knowledge, this is the first time that this variant has been implicated as a determinant of mortality and the finding warrants further investigation in other cohorts with DS.

Conclusions: This study shows negative associations of nine AD-derived SNPs with DAD in DS. This may be due to the modest size of our cohort, which may indicate that our study is insufficiently powered to pick up such associations. We cannot conclusively exclude a role for these SNPS in DAD in DS. Clearly, efforts to investigate genetic variants with small effects on disease risk require a much larger cohort of individuals with DS. In fact, we hypothesize that a sample size of 4465 individuals with DS would be needed to determine the role in DAD in DS of the nine AD-derived SNPs investigated in this study. We therefore recommend that all national and international clinics with access to individuals with DS should contribute DNA samples to form DS consortia.
\end{abstract}

Keywords: Down syndrome, Dementia, Alzheimer's disease, SNPs

\footnotetext{
* Correspondence: ashok.patel@coventry.ac.uk

${ }^{1}$ Department of Biomolecular and Sport Sciences, Faculty of Health and Life Sciences, Coventry University, Coventry, UK

Full list of author information is available at the end of the article
} 


\section{Background}

Down's syndrome (DS) is caused typically by a complete, or occasionally partial, triplication of chromosome 21 and has an incidence of approximately 1/1000 live births. The phenotype is complex and variable, primarily characterised by cognitive and language dysfunction coupled with sensory and neuromotor deficits and a neuropathology resulting in decreased brain size and weight [1]. DS is also characterised by congenital heart and bowel problems [2] and increased mortality rates both in early and later stages of life [3].

Evidence indicates that the dementia in DS is in fact Alzheimer's disease (AD) $[4,5]$. It is widely accepted that individuals with DS are much more likely to develop dementia of $\mathrm{AD}$ (DAD) than the general population, especially over the age of 35 years, [6,7]. Virtually all individuals with DS are likely to develop the neuropathological changes characteristic of AD by the age of 40 years; these include deposits of extracellular betaamyloid in neuritic plaques and intracellular neurofibrillary tangles [8]. However, despite the nearly universal occurrence of $\mathrm{AD}$ pathology by this age, it is clear that not all of these individuals develop clinical psychopathology of AD. A number of studies have shown that there is wide variation in the age of onset of dementia, from 38 to 70 years, with an average age at onset between 50 and 55 years $[9,10]$. This variation may be explained by a number of factors, including methodological difficulties in diagnosis of DAD in this population [11], triplication of the beta-amyloid precursor protein (APP) gene [12], $A P O E$ genotypes [6,13], gender [14] and a number of unknown genetic variants.

The neuropathological manifestations of DAD in DS have been attributed to triplication and over-expression of the APP gene located on chromosome 21 [12]. However, factors other than APP triplication must be responsible for the individual differences in susceptibility to the formation of fibrillised plaques and for the wide range in age at onset of dementia [6]. In the general population the gene coding for apolipoprotein $\mathrm{E}(A P O E)$ on chromosome 19 has been shown to modulate the risk of $A D$ in some studies. The $\varepsilon 4$ allele of APOE is associated with earlier age at onset and increased risk of AD [15-19] whilst the APOE $\varepsilon 2$ allele may reduce the risk of dementia in heterozygous carriers [20,21].

A number of studies have shown an association between the APOE $\varepsilon 4$ allele and an increased risk of DAD in individuals with DS $[6,13,22,23]$, but other studies have shown conflicting results [24-26]. There is evidence that APOE $\varepsilon 2$ is associated with increased longevity in DS $[27,28]$ and a potential protective effect on DAD [28-30], but these effects have not been confirmed by all studies [13,22,23]. Similarly, the influence of the APOE $\varepsilon 4$ allele on early mortality in individuals with DS [13,31] is subject to dispute [32].
A number of genes besides APOE have been implicated in susceptibility to DAD in individuals with DS, including TNF- $\alpha$ [24], BACE 1 [33], PSEN [34], SORL1 [35], ALDH18A1 and RUNX1 [36].

Recent collaborative genome-wide association studies of large case control data sets of individuals with $\mathrm{AD}$ have revealed new risk variants for dementia, as well as confirming previously identified risk variants [36,37]. Our present understanding of the genetic architecture of $\mathrm{AD}$ suggests that at least ten loci contribute to disease risk; APOE, CR1, CLU, PICALM, BIN1, EPHA1, MS4A, $C D 33, C D 2 A P$ and $A B C A 7$. As described above, the contribution of $A P O E$ to predisposition to dementia in DS has been widely studied [38], but the influence of the other nine risk variants on the development of DAD has yet to be investigated. The aim of our study, therefore, was to characterise the contribution of these AD susceptibility loci in the general population to the risk of DAD in a cohort of individuals with DS, to determine whether the two diseases have a common genetic basis.

\section{Methods \\ Participants}

Three hundred and four adults with DS (16 years and above) of white Caucasian ancestry, known to the local clinical services and voluntary organizations, were recruited into the study. Consent or assent was obtained as was appropriate. All participants resided in the West Midlands, United Kingdom. Ethical Committee approval was obtained from the local authority with approval from the NHS Trust.

\section{Procedures}

A prospective cohort design was used, with a range of two to 14 sequential assessments over the course of the follow up. Approximately $80 \%$ of participants had cytogenetic tests. Of these, 222 had trisomy 21, 12 had trisomy 21 translocation, 7 had trisomy 21 mosaicism, 1 had partial trisomy 21 and 1 had trisomy 21 and 48XXY. Some individuals did not consent to give blood for cytogenetic tests, or blood could not be obtained from them. Baseline assessment included a standard full psychiatric history and mental state examination. Mental disorders were diagnosed using the ICD-10 Symptom Checklist for Mental Disorders [39] according to ICD-10 research criteria [40]. An ascertainment of severity of dementia according to ICD-10 criteria [41] was made along with a physical examination (including an assessment of hearing and vision). There was also a comprehensive review of medical records, haematological, biochemical, and thyroid screening and a comprehensive review of all prescribed medications. Participants diagnosed with mental or physical disorders were treated appropriately and then 
followed up. Dementia in Alzheimer's disease was determined according to ICD-10 research criteria [40].

\section{SNP selection and genotyping}

Nine SNPs that had previously been robustly associated with late-onset Alzheimer's disease $\left(p<5 \times 10^{-8}\right)$ were genotyped in 295 subjects with Down's syndrome. These SNPs were in or near the CR1 (rs3818361), BIN1 (rs744373), CD2AP (rs9349407), EPHA1 (rs11767557), CLU (rs1532278), MS4A6A/4A (rs610932), PICALM (rs561655), $A B C A 7$ (rs3764650) and CD33 (rs3865444) genes [37]. Genotyping was performed by KBioscience (Hertfordshire, UK) using the KASP ${ }^{\mathrm{Ts}}$ genotyping method (www.lcggenomics.com/genotyping). The DNA samples of 268 subjects, both with $(\mathrm{N}=109)$ and without $(\mathrm{N}=159)$ dementia, demonstrated genotyping success rates greater than $75 \%$ over the 9 SNPs and were included in the main analyses. One hundred and twenty-five samples (47\%) were genotyped in duplicate for all SNPs. Genotypes were called independently and an error rate of zero was observed.

\section{Statistical analyses}

Cox proportional hazard regression was used to assess the effect of each SNP on the risk of dementia and mortality, including sex and level of intellectual disability as covariates. Age of onset of dementia or age at last assessment, or age at death or age at last assessment, were the time-toevent variables. As the minimum age at onset of dementia in the study was 38 years, only those non-demented subjects who were $=>38$ years of age at last assessment were included in the risk of DAD in DS analyses $\left(\mathrm{N}_{\text {total }}=225\right)$. The earliest age of death was 36 years, therefore only those surviving subjects who were $=>36$ years of age at last assessment were included in the mortality risk analysis $\left(\mathrm{N}_{\text {total }}=233\right)$. Mortality risk was estimated both in the entire cohort and within the subset of individuals who remained non-demented throughout the period of the study. SNPs were analysed using an additive model, coding each genotype as 0,1 or 2 Alzheimer's disease risk alleles. The single Hazard Ratio (HR) given for each SNP therefore represents a per risk allele effect.

For the risk of DAD in DS analyses $\left(\mathrm{N}_{\text {event }}=109\right)$, given minor allele frequencies of between $5-50 \%$, this study had $80 \%$ power to detect HRs in the region of $3.43-1.71$. Respective estimates for the mortality analyses $\left(\mathrm{N}_{\text {event }}=80\right)$, given the same allele frequencies, were 4.21-1.87. Given the modest effect sizes of the studied SNPs on the risk of Alzheimer's disease (reported odds ratios of 1.1-1.23 $[36,37])$, it was unlikely that adequate statistical power could be achieved for the analysis of individual SNPs in DAD using the current study's modest sample size. We therefore created a genetic risk score (GRS), calculated as the total number of Alzheimer's disease risk alleles within each individual, using those subjects with a $100 \%$ genotyping success rate $(N=243)$. The GRS was used to investigate whether genetic susceptibility for Alzheimer's disease in the general population overlapped with that for DAD in DS. All DAD in DS analyses were adjusted for APOE using SNP rs429358 as a proxy. Throughout this manuscript associations are referred to as nominally significant $(p<0.05)$ or study-wide significant (corrected for the 9 independent SNPs; $\mathrm{p}<5.5 \times 10^{-3}$ ). All analyses were conducted using $\mathrm{R}$ (www.R-project.org) or STATA IC V10.1 (Stata Corporation, College Station, TX, USA).

\section{Results \\ DAD in DS}

One SNP was nominally associated with the development of DAD in DS; the PICALM rs561655 variant appeared to reduce the risk of $\mathrm{DAD}(\mathrm{HR}=0.72, \mathrm{p}=0.02$; Table 1$)$. In contrast, six of the nine variants had hazard ratios greater than 1, although none of these was significantly associated with the development of dementia (Table 1). The combined GRS was not associated with DAD in DS $(\mathrm{HR}=0.98, p=0.78$; Table 1$)$.

\section{Mortality}

In the overall cohort, the PICALM rs561655 variant was nominally associated with a reduced risk of mortality $(\mathrm{HR}=0.71, p=0.048)$ whilst the CR1 rs3818361 variant increased the risk of early mortality $(\mathrm{HR}=1.65, p=$ $5.36 \times 10^{-3}$ ) (Table 2); this latter association achieved study-wide significance. In the non-demented group, the effect of the $C R 1$ variant was more pronounced $\left(\mathrm{HR}=2.33, p=4.08 \times 10^{-3}\right)$, whilst that of the PICALM SNP disappeared. Variants in or near CD33 and CD2AP also demonstrated weak but nominally significant associations with mortality (Table 2).

The GRS was not significantly associated with mortality in either the overall cohort or the non-demented subset (Table 2).

\section{Discussion}

To our knowledge, this is first study to investigate the effects of nine of the GWAS-derived susceptibility variants for Alzheimer's disease in the general population on the development of DAD in DS. The CR1 (rs3818361), BIN1 (rs744373), CD2AP (rs9349407), EPHA1 (rs11767557), CLU (rs1532278), MS4A6A/4A (rs610932), ABCA7 (rs3764650) and CD33 (rs3865444) SNPs showed no significant association with dementia in our cohort of individuals with DS, either singly or as part of a genetic risk score. A nominally significant association was observed with the PICALM rs561655 variant, but the direction of effect was opposite to that expected from earlier studies of Alzheimer's disease. 
Table 1 Association between SNPs and DAD in DS

\begin{tabular}{|c|c|c|c|c|c|}
\hline Nearest gene & SNP & Risk allele & Hazard ratio & SE & $p$-value \\
\hline$C R 1$ & rs3818361 & A & 1.10 & 0.17 & 0.59 \\
\hline BIN1 & rs744373 & G & 1.16 & 0.16 & 0.36 \\
\hline$C D 2 A P$ & rs9349407 & C & 0.99 & 0.15 & 0.93 \\
\hline EPHA1 & rs11767557 & $\mathrm{T}$ & 1.03 & 0.16 & 0.86 \\
\hline$C L U$ & rs1532278 & C & 1.05 & 0.13 & 0.69 \\
\hline$M S 4 A 6 A$ & rs610932 & G & 1.03 & 0.15 & 0.83 \\
\hline PICALM & rs561655 & A & 0.67 & 0.14 & $5.89 \times 10^{-3}$ \\
\hline$A B C A 7$ & rs3764650 & G & 1.09 & 0.29 & 0.76 \\
\hline CD33 & rs3865444 & C & 0.83 & 0.15 & 0.22 \\
\hline Genetic risk score & - & - & 0.97 & 0.06 & 0.66 \\
\hline
\end{tabular}

Covariates included in the analyses were sex, intellectual disability and APOE genotype.

Interestingly the CR1 rs3818361 variant appeared to be associated with premature mortality in our cohort, particularly in the subjects without dementia. To our knowledge, this is the first time that this variant has been implicated as a determinant of early mortality and the finding warrants further investigation in other cohorts with DS.

There is considerable evidence that there is a great deal of similarity between AD and dementia in DS [5] and it would be reasonable to expect a similar genetic predisposition in both conditions. A number of published studies that have investigated the genetic predisposition to DAD in DS and the sizes of cohorts with DS in these studies have ranged from 52 to 425 [22,30]. These studies, like the current investigation, were underpowered to detect effect sizes of the magnitude reported for recent Alzheimer's disease susceptibility variants. Replication studies have been undertaken to detect genetic variants associated with $\mathrm{AD}$ using relatively large numbers of individuals with $\mathrm{AD}$ and matched controls. When case control cohort sizes were examined in three such robust studies, they have ranged from 1829 to 3287 individuals with $\mathrm{AD}$ in the general population, and 2576 to 4396 matched controls [42-44] Given a hypothetical genetic variant associated with DAD in DS with a HR of 1.15 and a minor allele frequency of 0.25 (not unreasonable estimates based upon the large Alzheimer's disease GWAS previously mentioned) and a 'failure rate' of 0.48 (the proportion of subjects who developed dementia in the present study), to have $80 \%$ power at an alpha of 0.05 we would need a sample size of 4465 subjects with DS. Due to this lack of power we cannot conclusively exclude a role for these SNPs in DAD in DS, despite the lack of association demonstrated in this study. It is also possible that the lack of significant associations that we observed are due to the fact that only one variant per locus was investigated. The variants identified to be associated with Alzheimers's disease in recent GWAS are not aetiological variants [37], the hypothesis being that they are proxies in linkage disequilibrium with variants that exert a direct effect.

Table 2 Association between genetic variants and mortality

\begin{tabular}{|c|c|c|c|c|c|c|c|c|c|c|c|}
\hline \multirow[b]{2}{*}{ Nearest gene } & \multirow[b]{2}{*}{ SNP } & \multirow{2}{*}{$\begin{array}{c}\text { Risk allele } \\
\text { A }\end{array}$} & \multicolumn{3}{|c|}{ All subjects $(\mathrm{N}=233)^{*}$} & \multicolumn{3}{|c|}{$\begin{array}{l}\text { Subjects with Dementia } \\
(N=109)^{* *}\end{array}$} & \multicolumn{3}{|c|}{$\begin{array}{l}\text { Subjects without dementia } \\
\qquad(N=124)^{* *}\end{array}$} \\
\hline & & & Hazard ratio & SE & $p$-value & Hazard ratio & SE & $p$-value & Hazard ratio & SE & $p$-value \\
\hline CR1 & rs3818361 & G & 1.65 & 0.18 & $5.36 \times 10^{-3}$ & 2.33 & 0.29 & $4.08 \times 10^{-3}$ & 1.35 & 0.23 & 0.19 \\
\hline BIN1 & rs744373 & C & 1.05 & 0.20 & 0.82 & 1.34 & 0.44 & 0.51 & 0.94 & 0.25 & 0.81 \\
\hline$C D 2 A P$ & rs9349407 & $\mathrm{T}$ & 1.10 & 0.18 & 0.61 & 1.92 & 0.31 & 0.04 & 0.82 & 0.23 & 0.40 \\
\hline EPHA1 & rs11767557 & C & 1.23 & 0.19 & 0.29 & 0.76 & 0.35 & 0.44 & 1.47 & 0.24 & 0.10 \\
\hline$C L U$ & rs1532278 & G & 1.17 & 0.16 & 0.33 & 0.89 & 0.32 & 0.73 & 1.27 & 0.20 & 0.23 \\
\hline MS4A6A & rs610932 & A & 0.72 & 0.18 & 0.07 & 1.02 & 0.34 & 0.95 & 0.64 & 0.21 & 0.03 \\
\hline PICALM & rs561655 & G & 0.71 & 0.17 & 0.05 & 0.94 & 0.36 & 0.86 & 0.64 & 0.21 & 0.04 \\
\hline$A B C A 7$ & rs3764650 & C & 1.08 & 0.33 & 0.81 & 1.27 & 0.54 & 0.65 & 0.74 & 0.46 & 0.52 \\
\hline$C D 33$ & rs3865444 & - & 0.73 & 0.18 & 0.08 & 0.53 & 0.33 & 0.05 & 0.91 & 0.21 & 0.67 \\
\hline Genetic risk score & - & & 1.70 & 0.25 & 0.03 & 3.13 & 0.52 & 0.03 & 1.54 & 0.28 & 0.13 \\
\hline
\end{tabular}

*Covariates included in the analyses were sex, intellectual disability and dementia; **Covariates included in the analyses were sex and intellectual disability. 
It is therefore possible that by restricting our coverage of the loci in question, we may have missed associations with other genetic variants, due to differences in LD patterns. Investigation of a greater number of variants on these susceptibility loci is needed in future studies.

Clearly efforts to investigate genetic variants with small effects on disease risk require a much larger cohort of individuals with DS. A UK national database and DNA resource for DS would be an invaluable resource for researchers to elucidate risk alleles for DAD in DS. We therefore recommend that all national and international clinics with access to individuals with DS should contribute DNA samples to form DS consortia. These resources would facilitate well-powered genome-wide genetic studies to elucidate the risk variants that contribute to DAD in DS and investigate associations with risk variants implicated in other forms of dementia.

\section{Conclusions}

Nine SNPs, previously shown to contribute to the predisposition to $\mathrm{AD}$, showed no association with DAD in DS in this study. However, we cannot exclude a role for these SNPs in DAD in DS, as our study is insufficiently powered to pick up genetic variants with small effects on disease.

\section{Competing interests}

The authors declare that they have no competing interests.

\section{Author's contributions}

VP and HA collected blood from individuals with DS and undertook mental health assessments, SDR did the statistical analysis and contributed to drafting of paper, A Patel, SDR and VP contributed to the design of the study, A Patel drafted the paper, MAK contributed to drafting of the paper, SCB initiated the original idea to examine the DS cohort for genetic risk for dementia and along with $\mathrm{AHB}$ contributed to the drafting of the paper. AP undertook data collection. All authors read and approved the final manuscript.

\section{Author details}

${ }^{1}$ Department of Biomolecular and Sport Sciences, Faculty of Health and Life Sciences, Coventry University, Coventry, UK. ${ }^{2}$ College of Medical and Dental Sciences, University of Birmingham, Birmingham, UK. ${ }^{3}$ Institute of Life

Science, Swansea University, Swansea, UK. ${ }^{4}$ Diabetes Centre, Heart of England NHS foundation Trust, Birmingham, UK. ${ }^{5}$ Nottingham University, Nottingham, UK. ${ }^{6}$ South Birmingham Primary Care Trust, Birmingham, UK. ${ }^{7}$ Liverpool John Moore University, Liverpool, UK.

Received: 8 July 2013 Accepted: 4 December 2013

Published: 17 January 2014

\section{References}

1. Mrak RE, Griffin WS: Trisomy 21 and the brain. J Neuropathol Exp Neurol 2004, 63(7):679-685.

2. Vis JC, Duffels MG, Winter MM, Weijerman ME, Cobben JM, Huisman SA, Mulder BJ: Down syndrome: a cardiovascular perspective. J Intellect Disabil Res 2009, 53(5):419-425.

3. Yang Q, Rasmussen SA, Friedman JM: Mortality associated with Down's syndrome in the USA from 1983 to 1997: a population-based study. Lancet 2002, 359(9311):1019.

4. Mann DM: The pathological association between Down syndrome and Alzheimer disease. Mech Ageing Dev 1988, 43(2):99-136.
5. Ness S, Rafii M, Aisen P, Krams M, Silverman W, Manji H: Down's syndrome and Alzheimer's disease: towards secondary prevention. Nat Rev Drug Discov 2012, 11(9):655-656

6. Schupf N, Sergievsky GH: Genetic and host factors for dementia in Down's syndrome. Br J Psychiatry 2002, 180:405-410

7. Oliver C, Holland AJ: Down's syndrome and Alzheimer's disease: a review. Psychol Med 1986, 16(2):307-322.

8. Wisniewski KE, Dalton AJ, McLachlan C, Wen GY, Wisniewski HM: Alzheimer's disease in Down's syndrome: clinicopathologic studies. Neurology 1985, 35(7):957-961.

9. Lai F, Williams RS: A prospective study of Alzheimer disease in Down syndrome. Arch Neurol 1989, 46(8):849-853.

10. Prasher VP, Krishnan VH: Mental disorders and adaptive behaviour in people with Down's syndrome. Br J Psychiatry 1993, 162:848-850.

11. Nieuwenhuis-Mark RE: Diagnosing Alzheimer's dementia in Down syndrome: problems and possible solutions. Res Dev Disabil 2009, 30(5):827-838.

12. Rumble B, Retallack R, Hilbich C, Simms G, Multhaup G, Martins R, Hockey A, Montgomery P, Beyreuther K, Masters CL: Amyloid A4 protein and its precursor in Down's syndrome and Alzheimer's disease. N Engl J Med 1989, 320(22):1446-1452

13. Prasher VP, Sajith SG, Rees SD, Patel A, Tewari S, Schupf N, Zigman WB: Significant effect of APOE epsilon 4 genotype on the risk of dementia in Alzheimer's disease and mortality in persons with Down syndrome. Int J Geriatr Psychiatry 2008, 23(11):1134-1140.

14. Coppus AM, Evenhuis HM, Verberne GJ, Visser FE, Eikelenboom P, Van Gool WA, Janssens AC, Van Duijn CM: Early age at menopause is associated with increased risk of dementia and mortality in women with Down syndrome. J Alzheimers Dis 2010, 19(2):545-550.

15. Corder EH, Saunders AM, Strittmatter WJ, Schmechel DE, Gaskell PC, Small GW, Roses AD, Haines JL, Pericak-Vance MA: Gene dose of apolipoprotein E type 4 allele and the risk of Alzheimer's disease in late onset families. Science 1993, 261(5123):921-923.

16. Mayeux R, Stern Y, Ottman R, Tatemichi TK, Tang MX, Maestre G, Ngai C, Tycko B, Ginsberg $H$ : The apolipoprotein epsilon 4 allele in patients with Alzheimer's disease. Ann Neurol 1993, 34(5):752-754.

17. Saunders AM, Schmader K, Breitner JC, Benson MD, Brown WT, Goldfarb L, Goldgaber D, Manwaring MG, Szymanski MH, McCown N: Apolipoprotein E epsilon 4 allele distributions in late-onset Alzheimer's disease and in other amyloid-forming diseases. Lancet 1993, 342(8873):710-711.

18. Meyer MR, Tschanz JT, Norton MC, Welsh-Bohmer KA, Steffens DC, Wyse BW, Breitner JC: APOE genotype predicts when-not whether-one is predisposed to develop Alzheimer disease. Nat Genet 1998, 19(4):321-322.

19. Khachaturian AS, Corcoran CD, Mayer LS, Zandi PP, Breitner JC, Cache County Study Investigators: Apolipoprotein E epsilon4 count affects age at onset of Alzheimer disease, but not lifetime susceptibility: The Cache County Study. Arch Gen Psychiatry 2004, 61(5):518-524.

20. Corder EH, Saunders AM, Risch NJ, Strittmatter WJ, Schmechel DE, Gaskell PC Jr, Rimmler JB, Locke PA, Conneally PM, Schmader KE: Protective effect of apolipoprotein E type 2 allele for late onset Alzheimer disease. Nat Genet 1994, 7(2):180-184.

21. Roses AD, Saunders AM: APOE is a major susceptibility gene for Alzheimer's disease. Curr Opin Biotechnol 1994, 5(6):663-667.

22. Coppus AMW, Evenhuis HM, Verberne G, Visser FE, Arias-Vasquez A, SayedTabatabaei F, Vergeer-Drop J, Eikelenboom P, Van Gool WA, Van Duijn CM: The impact of apolipoprotein $\mathrm{E}$ on dementia in persons with Down's syndrome. Neurobiol Aging 2008, 29(6):828-835.

23. Deb S, Braganza J, Norton N, Williams H, Kehoe PG, Williams J, Owen MJ: APOE epsilon 4 influences the manifestation of Alzheimer's disease in adults with Down's syndrome. Br J Psychiatry 2000, 176:468-472.

24. Lucarelli P, Piciullo A, Verdecchia M, Palmarino M, Arpino C, Curatolo P: The role of -850 tumor necrosis factor-a and apolipoprotein E genetic polymorphism in patients with Down's syndrome-related dementia. Neurosci Lett 2003, 352(1):29.

25. Anello G, Gueant J, Romano C, Barone C, Pettinato R, Pillot T, Rodriguez R, Romano A, Bosco P: Allele varepsilon4 of apolipoprotein E gene is less frequent in Down syndrome patient of the Sicilian population and has no influence on the grade of mental retardation. Neurosci Lett 2001, 306(1-2):129-131.

26. Van Gool WA, Evenhuis HM, Van Duijn CM: A case-control study of apolipoprotein E genotypes in Alzheimer's disease associated with 
Down's syndrome. Dutch Study Group on Down's Syndrome and Ageing. Ann Neurol 1995, 38(2):225-230.

27. Prasher VP, Chowdhury TA, Rowe BR, Bain SC: ApoE genotype and Alzheimer's disease in adults with Down syndrome: meta-analysis. Am J Ment Retard 1997, 102(2):103-110.

28. Tyrrell J, Cosgrave M, Hawi Z, McPherson J, O'Brien C, McCalvert J, McLaughlin M, Lawlor B, Gill M: A protective effect of apolipoprotein E e2 allele on dementia in Down's syndrome. Biol Psychiatry 1998, 43(6):397-400

29. Lai F, Kammann E, Rebeck GW, Anderson A, Chen Y, Nixon RA: APOE genotype and gender effects on Alzheimer disease in 100 adults with Down syndrome. Neurology 1999, 53(2):331-336.

30. Rubinsztein DC, Hon J, Stevens F, Pyrah I, Tysoe C, Huppert FA, Easton DF, Holland AJ: Apo E genotypes and risk of dementia in Down syndrome. Am J Med Genet 1999, 88(4):344-347.

31. Folin M, Baiguera S, Conconi MT, Pati T, Grandi C, Parnigotto PP, Nussdorfer GG: The impact of risk factors of Alzheimer's disease in the Down syndrome. Int J Mol Med 2003, 11(2):267-270.

32. Edland SD, Wijsman EM, Schoder-Ehri GL, Leverenz JB: Little evidence of reduced survival to adulthood of apoE epsilon4 homozygotes in Down's syndrome. Neuroreport 1997, 8(16):3463-3465.

33. Gold G, Blouin JL, Herrmann FR, Michon A, Mulligan R, Duriaux Sail G, Bouras C, Giannakopoulos P, Antonarakis SE: Specific BACE1 genotypes provide additional risk for late-onset Alzheimer disease in APOE epsilon 4 carriers. Am J Med Genet B Neuropsychiatr Genet 2003, 119B(1):44-47.

34. Lucarelli P, Piciullo A, Palmarino M, Verdecchia M, Saccucci P, Arpino C, Curatolo P: Association between presenilin-1-48C/T polymorphism and Down's syndrome. Neurosci Lett 2004, 367(1):88-91.

35. Lee JH, Chulikavit M, Pang D, Zigman WB, Silverman W, Schupf N: Association between genetic variants in sortilin-related receptor 1 (SORL1) and Alzheimer's disease in adults with Down syndrome. Neurosci Lett 2007, 425(2):105-109.

36. Naj AC, Jun G, Beecham GW, Wang LS, Vardarajan BN, Buros J, Gallins PJ, Buxbaum JD, Jarvik GP, Crane PK, Larson EB, Bird TD, Boeve BF, Graff-Radford NR, De Jager PL, Evans D, Schneider JA, Carrasquillo MM, Ertekin-Taner N, Younkin SG, Cruchaga C, Kauwe JS, Nowotny P, Kramer P, Hardy J, Huentelman MJ, Myers AJ, Barmada MM, Demirci FY, Baldwin CT, et al: Common variants at MS4A4/MS4A6E, CD2AP, CD33 and EPHA1 are associated with late-onset Alzheimer's disease. Nat Genet 2011, 43(5):436-441.

37. Hollingworth P, Harold D, Sims R, Gerrish A, Lambert JC, Carrasquillo MM, Abraham R, Hamshere ML, Pahwa JS, Moskvina V, Dowzell K, Jones N, Stretton A, Thomas C, Richards A, Ivanov D, Widdowson C, Chapman J, Lovestone S, Powell J, Proitsi P, Lupton MK, Brayne C, Rubinsztein DC, Gill M, Lawlor B, Lynch A, Brown KS, Passmore PA, Craig D, et al: Common variants at ABCA7, MS4A6A/MS4A4E, EPHA1, CD33 and CD2AP are associated with Alzheimer's disease. Nat Genet 2011, 43(5):429-435.

38. Patel A, Rees SD, Kelly MA, Bain SC, Barnett AH, Thalitaya D, Prasher VP: Association of variants within APOE, SORL1, RUNX1, BACE1 and ALDH18A1 with dementia in Alzheimer's disease in subjects with Down syndrome. Neurosci Lett 2011, 487(2):144-148.

39. Janca A, Ustun TB, Van Drimmelen J, Dittmann V, Isaac M: ICD-10 Symptom Checklist for Mental Disorders, Version 1.1. Geneva: Division of Mental Health, World Health Organization; 1994.

40. The ICD-10 Classification of Mental and Behavioural Disorders. Diagnostic Criteria for Research. Geneva: World Health Organisation; 1993a.

41. The ICD-10 Classification of Mental and Behavioural Disorders. Clinical Descriptions and Diagnostic Guidelines. Geneva: World health Organization; 1992b.

42. Reitz C, Jun G, Naj A, Rajbhandary R, Vardarajan BN, Wang LS, Valladares O, Lin CF, Larson EB, Graff-Radford NR, Evans D, De Jager PL, Crane PK, Buxbaum JD, Murrell JR, Raj T, Ertekin-Taner N, Logue M, Baldwin CT, Green RC, Barnes LL, Cantwell LB, Fallin MD, Go RC, Griffith P, Obisesan TO, Manly $\mathrm{JJ}$, Lunetta KL, Kamboh MI, Lopez OL, et al: Alzheimer Disease Genetics Consortium: Variants in the ATP-binding cassette transporter (ABCA7), apolipoprotein E 4, and the risk of late-onset Alzheimer disease in African Americans. JAMA 2013, 309(14):1483-1492.
43. Carrasquillo MM, Belbin O, Hunter TA, Ma L, Bisceglio GD, Zou F, Crook JE, Pankratz VS, Sando SB, Aasly JO, Barcikowska M, Wszolek ZK, Dickson DW, Graff-Radford NR, Petersen RC, Morgan K, Younkin SG: Replication of BIN1 association with Alzheimer's disease and evaluation of genetic interactions. J Alzheimers Dis 2011, 24(4):751-758.

44. Carrasquillo MM, Belbin O, Hunter TA, Ma L, Bisceglio GD, Zou F, Crook JE, Pankratz VS, Dickson DW, Graff-Radford NR, Petersen RC, Morgan K, Younkin SG: Replication of CLU, CR1, and PICALM associations with alzheimer disease. Arch Neurol 2010, 67(8):961-964.

doi:10.1186/1756-0500-7-42

Cite this article as: Patel et al:: Genetic variants conferring susceptibility to Alzheimer's disease in the general population; do they also predispose to dementia in Down's syndrome. BMC Research Notes 2014 7:42.

\section{Submit your next manuscript to BioMed Central and take full advantage of:}

- Convenient online submission

- Thorough peer review

- No space constraints or color figure charges

- Immediate publication on acceptance

- Inclusion in PubMed, CAS, Scopus and Google Scholar

- Research which is freely available for redistribution 